\title{
Transient Measurements of Temperature and Radiation Intensity in Spherical Microgravity Diffusion Flames
}

\author{
Melissa K. Chernovsky ${ }^{*}$ and Arvind Atreya ${ }^{\dagger}$ \\ University of Michigan, Department of Mechanical Engineering, Ann Arbor, MI, 48109 \\ and \\ Kurt R. Sacksteder \\ NASA Glenn Research Center, Cleveland, $\mathrm{OH}, 44135$
}

\begin{abstract}
This work reports transient measurements of flame growth, temperature field, and hemispherical spectral radiation emission in expanding spherical diffusion flames. These measurements were made to study the effect of various diluents $\left(\mathrm{N}_{2}, \mathrm{CO}_{2}, \mathrm{He}\right)$ on properties of microgravity diffusion flames. Diluents were chosen to replace nitrogen on the oxidizer side of the flame, maintaining a constant oxygen composition. Experiments were conducted at atmospheric pressure using a porous spherical burner aerodynamically supporting an ethylene $\left(\mathrm{C}_{2} \mathrm{H}_{4}\right)$ diffusion flame in an oxidizing atmosphere. A color CCD camera was used for visual observations and to obtain the flame growth rate. Temperature field was measured by an array of thermocouples that were corrected for radiation and conduction heat transfer and time constant. Radiation intensity was measured by an array of photo detectors sensitive to selected spectral regions. Experimental results show that Lewis number of the oxidizer does not have a dominant effect on flame growth. Influence of a $\mathrm{CO}_{2} / \mathrm{He}$ mixture despite controlling $\rho \mathrm{C}_{\mathrm{P}}$, the energy storage component of the reactant mixture in comparison to $\mathrm{N}_{2}$ diluent, reduced soot formation and flame temperature due to increased energy transfer. The $\mathrm{CO}_{2} / \mathrm{He}$ mixture increased the volume averaged temperature and lowered the flame emission indicating both an increase in heat transfer and reabsorption of the energy. Helium diluent lowered the flame temperature, increased the volume averaged temperature, and maintained flame emission. $\mathrm{CO}_{2}$ diluent lowered the flame temperature, decreased the volume averaged temperature, and also lowered flame emission.
\end{abstract}

\section{Introduction}

$\mathrm{F}$ IRE safety under microgravity $(\mu \mathrm{g})$ conditions is a practical concern in space applications and brings new research interests because fire suppression methods appropriate for $\mu \mathrm{g}$ conditions are significantly different from those developed for the normal gravity Earth environment. Thus a number of drop-tower $\mu \mathrm{g}$ experiments have been conducted in conjunction with numerical modeling in order to understand flame extinction mechanisms under $\mu \mathrm{g}$ experiments. From a fundamental standpoint, the absence of buoyancy in the $\mu \mathrm{g}$ environment naturally creates a spherically symmetric configuration, thereby allowing a one-dimensional model amenable to extensive parametric studies. Therefore, this work focuses on the characteristics of aerodynamically stabilized spherical diffusion flames that are subjected to gas radiation and extinction.

Spherical flames have been adopted in many previous studies of diffusion flames in $\mu \mathrm{g}^{1-5}$. The lack of convective effects causes hot combustion products to have a longer residence time enabling further dilution of fuel and oxidizer in the flame reaction zone. Gaseous combustion products, such as carbon dioxide $\left(\mathrm{CO}_{2}\right)$ and water $\left(\mathrm{H}_{2} \mathrm{O}\right)$ are strong radiative emitters; accumulation of these gases in high temperature reaction zones significantly enhances radiation heat loss. $\mathrm{CO}_{2}$, a particularly strong radiative absorber as well, exists in significant amounts in the interior region of

\footnotetext{
* Graduate Student, Department of Mechanical Engineering, 2350 Hayward St, AIAA Member.

${ }^{\dagger}$ Professor, Department of Mechanical Engineering, 2350 Hayward St, AIAA Member.

* Researcher, Microgravity Science Division, 21000 Brookpark Rd, AIAA Member.
} 
the spherical flame. This high concentration influences flame properties such as radiation emission and reabsorption, as well as reaction chemistry. It has been found that gas radiation is extremely important and must be accounted for in numerical models of $\mu \mathrm{g}$ counterflow ${ }^{6,7}$, droplet $^{8}$, and spherical ${ }^{2-5}$ diffusion flame configurations. It has also been found that optically thin and wide-band gas radiation models are unable to accurately predict similar experimental results, while optically thick statistical narrow-band models which account for radiation reabsorption have shown better comparisons $\mathrm{s}^{3,6,7,9}$.

The objective of the current work is to investigate the effects of various diluents with different radiative and nonradiative diluents on flame characteristics. Combinations of non-radiative (nitrogen $-\mathrm{N}_{2}$, helium - He) and reacting and radiative $\left(\mathrm{CO}_{2}\right)$ diluents are included in the oxidizer mixture for the diffusion flame. Similar research has been done to look at the effects of $\mathrm{CO}_{2}{ }^{10,11}$ on counterflow diffusion flames in normal gravity. Numerically, direct replacement of $\mathrm{CO}_{2}$ has been made with a non-reacting $\mathrm{CO}_{2}$ molecule ${ }^{12,13}$. Experimental realization of these radiation effects under $\mu \mathrm{g}$ conditions, however, is a challenging task. Individual diluents $\mathrm{He}$ and $\mathrm{CO}_{2}$ are also investigated for interest in potential use in increasing fire safety. In most previous experimental spherical diffusion flame studies, only the flame growth rate history was measured. Therefore, for better understanding of the effects of radiation on microgravity flames, the present study performed temperature field measurements as well as spectral radiation intensity measurements. Experimental results are presented in order to gain understanding of fundamental characteristics of diffusion flames and the importance of gas radiation.

\section{Experimental}

Experiments were conducted at the NASA Glenn 2.2 second drop tower using an experimental rig ${ }^{14}$ described in a few words here. A key feature of the experiment is the sealed cylindrical test chamber which allows for various oxidizer composition such as enhanced carbon dioxide or oxygen, enabling the investigation of radiative properties in microgravity diffusion flames. The diameter, length, and volume of the chamber are $25 \mathrm{~cm}, 56 \mathrm{~cm}$, and 27 liters, respectively. The combustion chamber has four window ports for optical measurements. The chamber contains the spherical burner, hot-wire ignition system, thermocouples, and photo detectors for spectral radiation measurements. The spherical burner with a diameter of $16 \mathrm{~mm}$ was constructed from low heat capacity ceramic foam material (100 pores per inch). An integrated plumbing system provided by NASA is used to deliver a metered single-gas flow. This system utilizes an in-line filter, a pressure regulator, a pressure transducer to monitor the regulated flow pressure, a metering valve, a solenoid valve, and a $500 \mathrm{cc}$ supply bottle. The flame is ignited by a coiled resistive wire igniter which is placed approximately $2 \mathrm{~mm}$ from the spherical burner surface. After ignition occurs, a solenoid quickly retracts the igniter arm in order to avoid disturbance of the established diffusion flame. The timesynchronized operation of the fuel delivery system and ignition sequence is controlled by a programmable on-board processor.

Several $\mu$ g experiments were conducted using ethylene $\left(\mathrm{C}_{2} \mathrm{H}_{4}\right)$ fuel, supplied at a total flow rate of $6 \mathrm{~cm}^{3} / \mathrm{s}(6.8 \mathrm{e}-$ $6 \mathrm{~kg} / \mathrm{s})$ into an oxidizer consisting of $21.0 \% \mathrm{O}_{2}$ and diluents at atmospheric pressure $(101.3 \mathrm{kPa})$. Ambient temperature of both fuel and oxidizer was $300 \mathrm{~K}$. The control mixture is composed of nitrogen, or air, $21.0 \% \mathrm{O} 2$ $79 \% \mathrm{~N}_{2}$. A test mixture using $21.0 \% \mathrm{O}_{2}$ reactant and diluents $\mathrm{CO}_{2}$ and $\mathrm{He}$ was selected to maintain the temperature dependent energy storage term $\rho(\mathrm{T}) * \mathrm{C}_{\mathrm{P}}(\mathrm{T})$ approximately constant in comparison to the $\mathrm{N}_{2}$ control mixture in order to minimize the thermal effect of different diluents. Consideration was also made to balance $C_{P}$ while maintaining a constant fuel flow rate. This condition is important with the resulting adiabatic flame temperatures nearly equivalent at the onset of the established flame. Test mixtures of $\mathrm{O}_{2}$ and $\mathrm{N}_{2}$ with individual diluents $\mathrm{CO}_{2}$ and $\mathrm{He}$ were also tested; note, these tests are not expected to have the same adiabatic flame temperatures. Table 1 details experiments and nomenclature presented in this work including properties of the reactant mixtures at $1000 \mathrm{~K}$, where $\rho \mathrm{C}_{\mathrm{P}}$ has units of $\mathrm{kJ} / \mathrm{m}^{3} \mathrm{~K}$. Transport and thermodynamic properties were calculated using Chemkin ${ }^{15}$ and Transport $^{16}$ packages.

Table 1

Mixture compositions for laminar diffusion flames, properties at $1000 \mathrm{~K}$

\begin{tabular}{cccccc}
\hline Flame & Fuel Mixture Vol. \% & Oxidizer Mixture Vol. \% & $\rho \mathrm{C}_{\mathrm{P}}$ & $\mathrm{Le}_{\mathrm{F}}$ & $\mathrm{Le}_{\mathrm{O}}$ \\
\hline $\mathrm{N} 2$ & $100 \mathrm{C}_{2} \mathrm{H}_{4}$ & $21 \mathrm{O}_{2}, 79 \mathrm{~N}_{2}$ & 0.404 & 0.84 & 1.09 \\
$20 \mathrm{CO} 2 \mathrm{Hemix}$ & $100 \mathrm{C}_{2} \mathrm{H}_{4}$ & $21 \mathrm{O}_{2}, 59 \mathrm{~N}_{2}, 7.1 \mathrm{CO}_{2}, 12.9 \mathrm{He}$ & 0.404 & 0.84 & 1.31 \\
$20 \mathrm{He}$ & $100 \mathrm{C}_{2} \mathrm{H}_{4}$ & $21 \mathrm{O}_{2}, 59 \mathrm{~N}_{2}, 20 \mathrm{He}$ & 0.375 & 0.84 & 1.50 \\
$20 \mathrm{CO} 2$ & $100 \mathrm{C}_{2} \mathrm{H}_{4}$ & $21 \mathrm{O}_{2}, 59 \mathrm{~N}_{2}, 20 \mathrm{CO}_{2}$ & 0.467 & 0.84 & 0.99 \\
$60 \mathrm{CO} 2 \mathrm{Hemix}$ & $100 \mathrm{C}_{2} \mathrm{H}_{4}$ & $21 \mathrm{O}_{2}, 17 \mathrm{~N}_{2}, 21.3 \mathrm{CO}_{2}, 40.7 \mathrm{He}$ & 0.401 & 0.84 & 1.7 \\
$60 \mathrm{He}$ & $100 \mathrm{C}_{2} \mathrm{H}_{4}$ & $21 \mathrm{O}_{2}, 19 \mathrm{~N}_{2}, 60 \mathrm{He}$ & 0.317 & 0.84 & 2.38 \\
$60 \mathrm{CO} 2$ & $100 \mathrm{C}_{2} \mathrm{H}_{4}$ & $21 \mathrm{O}_{2}, 19 \mathrm{~N}_{2}, 60 \mathrm{CO}_{2}$ & 0.562 & 0.84 & 0.86 \\
\hline
\end{tabular}


Data was collected by an onboard computer using twenty two data acquisition channels monitoring at $200 \mathrm{~Hz}$. Using the apparatus shown in Figure 1, the following measurements were made during a drop tower experiment: (i) Flame radius - was measured from images taken by a color CCD camera at 30 frames per second. Images were post-processed to determine the time evolution of the flame radius. (ii) Flame temperature - was measured by eight radially placed thermocouples, $76 \mu \mathrm{m}$ in diameter. The spherical burner surface temperature and two far-field positions were measured by K-type thermocouples, and S-type thermocouples were placed at five near-field positions to monitor the temperature history during the passing of the flame front. All thermocouples were uncoated and the data were post-processed to account for radiative and conductive heat transfer and response time of the thermocouple bead. Positions of the thermocouples measured from the centerline of the burner include the burner surface $(0.8 \mathrm{~cm})$ and radial positions ranging from $1.45-4.25 \mathrm{~cm}$. All thermocouples contribute to a comprehensive temperature field measurement of the flame front propagation. (iii) Flame radiation - was measured by five pairs of photodiodes and infrared detectors that quantify multiple radiation intensity wavelength regions in order to obtain fast spectral measurements of ultraviolet, visible, and infrared radiation. Time constants for the detectors are on the order of 0.1-100 $\mu \mathrm{s}$. Pairs of photo detectors are located in opposite window ports at a distance of $12 \mathrm{~cm}$ from the centrally oriented burner to view the entire combustion chamber. Data from the calibrated pairs are averaged and post-processed to represent distinct radiation wavelength bands.

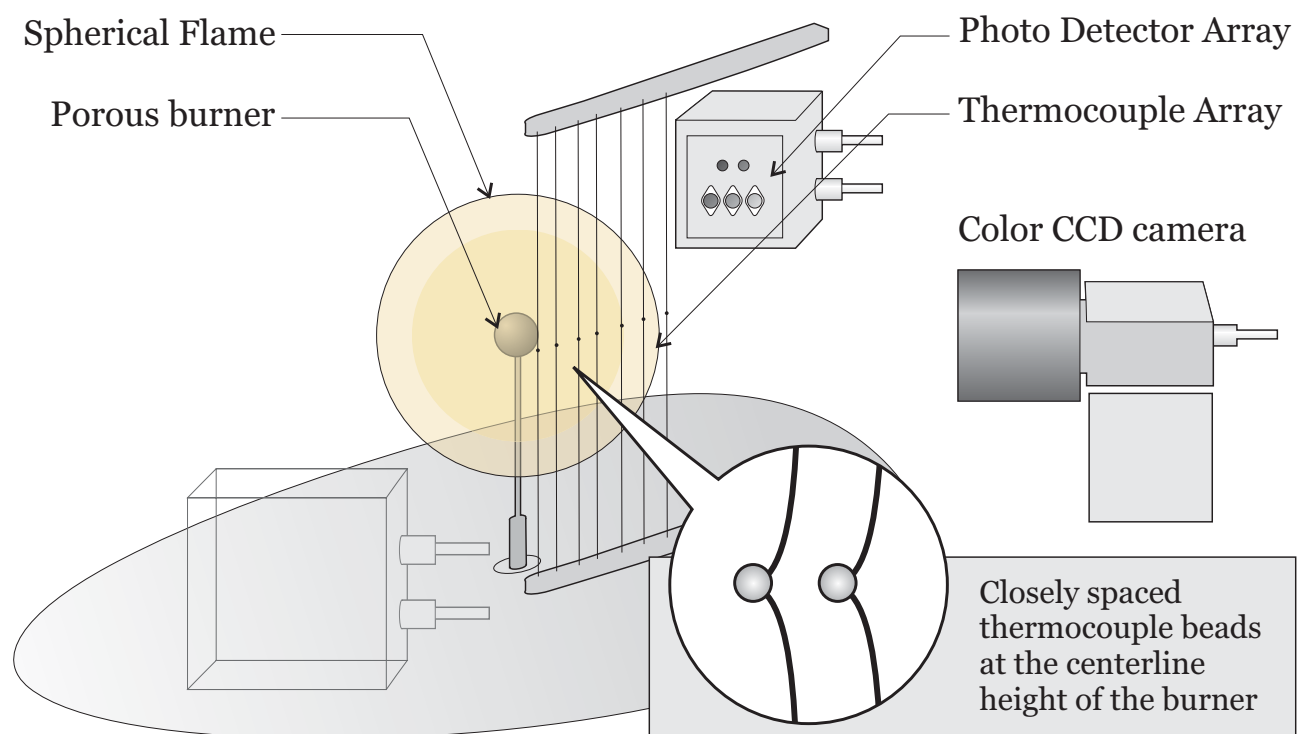

Figure 1. Experimental Science Layout. Position of thermocouples, photo detectors, and camera view angle for growth rate analysis.

\section{Results and Discussion}

As noted above one system is studied, with two diluent increments on the oxidizer side of the reaction zone (flames N2; 20CO2Hemix, 20He and 20CO2; and 60CO2Hemix, 60He and 60CO2). The reactant mixture with non-reacting, non-radiating $\mathrm{N}_{2}$ diluent is compared with a reacting and radiative counterpart mixture where $\mathrm{N}_{2}$ is replaced by a diluent mixture including $\mathrm{CO}_{2}$ and $\mathrm{He}$ to balance $\rho \mathrm{C}_{\mathrm{P}}$. Also $\mathrm{CO}_{2}$ and He diluents are compared individually with the $\mathrm{N}_{2}$ reactant and $\mathrm{CO}_{2} / \mathrm{He}$ mixture. $21 \% \mathrm{O}_{2}$ by volume is maintained and the balance of the oxidizer composition is $\mathrm{N}_{2}$.

\section{A. Flame Growth Rate}

Figures 2 and 3 show results of flame growth rate for the flames of interest. Uncertainty of the radius measurements was estimated to be less than $\pm 2 \%$ (at 95\% confidence level). For all $21 \%$ oxygen flames, the flame growth rate was found to be approximately equivalent within the uncertainty of the measurement. Comparing Fig. 2 with $20 \%$ diluent flames and Fig. 3 with $60 \%$ diluent flames did not show different flame growth rate behavior. These flames all had the same concentration of oxygen and ethylene fuel by volume. In comparison, $18 \% \mathrm{O}_{2}$ and $30 \% \mathrm{O}_{2}$ oxidizer flames with similar diluents tested were found to have $5 \%$ larger and $11 \%$ smaller growth rates, respectively (data not shown here). 


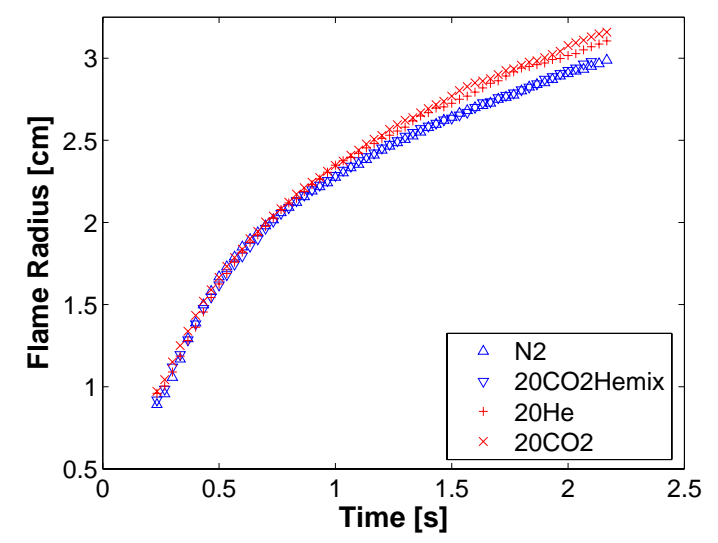

Figure 2. Growth of Flame Radius [cm] for $20 \%$ diluent flames. Radial averaged data at each video frame are plotted.

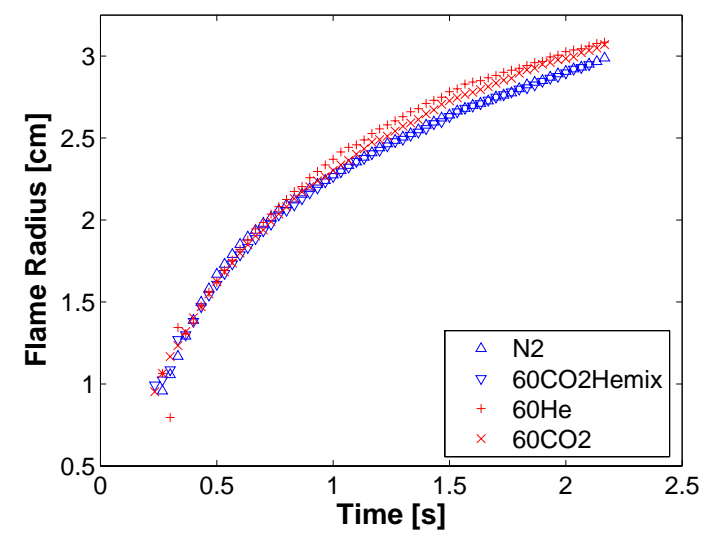

Figure 3. Growth of Flame Radius [cm] for $60 \%$ diluent flames. Radial averaged data at each video frame are plotted.

In Figs. 2 and 3, the single diluents flames, $(20 \mathrm{He}, 20 \mathrm{CO} 2,60 \mathrm{He}, 60 \mathrm{CO} 2)$ had a slightly larger flame growth compared to the N2, 20CO2Hemix, and 60CO2Hemix flames. Increasing the amount of test diluent in Fig. 3 did not widen the discrepancy, and further the results are not correlated because the $20 \mathrm{CO} 2$ flame was slightly larger than the $20 \mathrm{He}$ flame, while the $60 \mathrm{He}$ flame was slightly larger than the $60 \mathrm{CO} 2$ flame. The Lewis number on the oxidizer side, $\mathrm{Le}_{\mathrm{O}}$, is not shown to affect the flame growth behavior. The Lewis number is defined as the ratio of the thermal to mass diffusivity, where the latter is determined by the diffusivity of the reactant with respect to the neighboring diluent gases. In the present spherical configuration, $\mathrm{Le}_{\mathrm{O}}>1$ would lead to an increase in the steady flame radius. Based on the transport properties available in Chemkin ${ }^{15,16}$, the estimated $\mathrm{Le}_{\mathrm{O}}$ of the flames have large discrepancies as shown in Table 1. The helium and $\mathrm{CO} 2 / \mathrm{He}$ mixture flames have large Lewis numbers, yet the overall experimental growth data shows little effect of Le $\mathrm{O}_{\mathrm{O}}$. In Fig. 3, the $60 \mathrm{He}$ and $60 \mathrm{CO} 2 \mathrm{He}$ flames went through ignition instability where premixed flash ignitions and subsequent extinction zones were observed in sections of the spherical flame. This was strongly evident in the $60 \mathrm{He}$ flame where the entire flame became extinct as can be seen by the outlying point at the burner surface at approximately $0.3 \mathrm{~s}$. The flame was subsequently reignited by the igniter which had not finished the ignition sequence and retraction. It is suggested that high $\mathrm{Le}_{\mathrm{O}}$ have an effect on ignition, but overall $\mathrm{Le}_{\mathrm{O}}$ did not have an effect on the growth rate.

\section{B. Flame Temperature}

Figure 4 shows plots of gas temperature field versus time measured by eight thermocouples that were corrected for radiation and conduction heat transfer and time constant ${ }^{14}$. Radial positions of the thermocouples (TC) from the centerline of the burner in [cm] were TCB - 0.8 (burner edge); TC1 - 1.45; TC2 - 1.75; TC3 - 2.2; TC4 - 2.7; TC5 3.1; TC6 - 3.6; and TC7 - 4.2. Thermocouple positions have an uncertainty of $\pm 0.05 \mathrm{~cm}$. Corrected thermocouple temperatures have uncertainties (at the $95 \%$ confidence level) of $\pm 35 \mathrm{~K}$. The flame temperature evolution shown in Figs. 5 and 6 for the $20 \%$ dilution and $60 \%$ dilution flames, respectively, is estimated by thermocouple measurements when the flame passed through the radial position as shown by the dashed line in Fig. 4. Flame temperature decreased after the onset of the diffusion flame for all flames. However the initial flame temperature decrease was slight between $\mathrm{TC} 1$ and $\mathrm{TC} 2$ for the $20 \%$ diluent flames in Fig. 4 in comparison to the steeper temperature decline between $\mathrm{TC} 1$ and $\mathrm{TC} 2$ of the $60 \%$ diluent flames also in Fig. 4. Surface temperature of the porous ceramic burner, TCB, stabilized between 400 and $500 \mathrm{~K}$. Figures 7 and 8 show the volume averaged temperature calculated from eight discrete positional measurements in conjunction with the estimated flame temperature evolution for the $20 \%$ dilution and $60 \%$ dilution flames, respectively.

Comparing N2 and 20CO2Hemix in Figs. 4 and 7, the overall flame temperature decreased by approximately 50 $\mathrm{K}$. Similarly, the $60 \mathrm{CO} 2 \mathrm{Hemix}$ flame temperature decreased by approximately $100 \mathrm{~K}$, in comparison to the N2 flame. These three flames were designed to have the same $\rho C_{P}$. In addition to tracking the flame temperature, the radially positioned thermocouples provided measurements of the gas temperature on both the fuel and oxidizer side of the reaction zone. Because the flame growth rate is approximately equivalent, the temperature time history can be directly compared. Once the flame has passed the thermocouple position, the thermocouples track the interior temperature of the spherical flame. The internal temperatures represented by $\mathrm{TC} 1-3$, of the 20CO2Hemix flame in comparison to the $\mathrm{N} 2$ flame were approximately equivalent. This trend of the internal temperature was also 

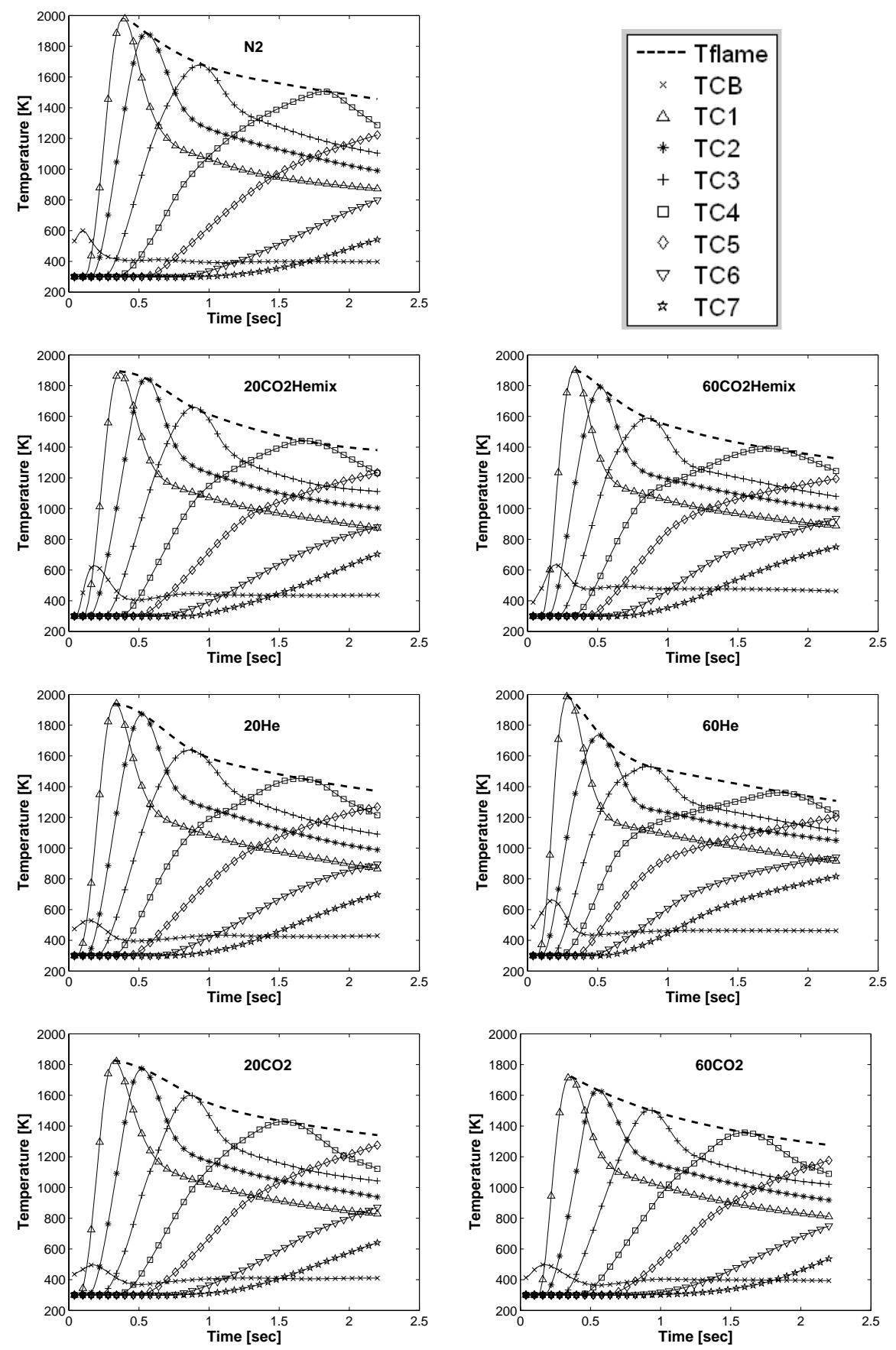

Figure 4. Gas temperature field versus time for 8 thermocouple positions and flame temperature evolution profile fit from thermocouple peak data. Flames N2, 20CO2Hemix, 20He, 20CO2, $60 \mathrm{CO} 2 \mathrm{Hemix}, 60 \mathrm{He}$, and $60 \mathrm{CO} 2$ are presented. Radial positions from the centerline of the burner in [cm] are: TCB - 0.8 (burner edge); TC1 - 1.45; TC2 - 1.75; TC3 - 2.2; TC4 - 2.7; TC5 - 3.1; TC6 - 3.6; and TC7 -4.2 ;

observed by the 60CO2Hemix flame in comparison to the $\mathrm{N} 2$ flame. Temperature gradients of far field positions represented by TC5 -7 , of the $20 \mathrm{CO} 2 \mathrm{Hemix}$ flame were noticed earlier and were higher in comparison to the N2 flame. The far field temperature gradients were further accentuated in the $60 \mathrm{CO} 2 \mathrm{Hemix}$ flame. The increased far- 
field temperatures of the 20CO2Hemix and $60 \mathrm{CO} 2 \mathrm{Hemix}$ flames resulted in a higher overall volume averaged temperature (Figs. 7 and 8, respectively) in comparison to the N2 flame despite the lower flame temperatures (Figs. 5 and 6 respectively). Increased temperature in the far field could be due to the effect of increased $\mathrm{Le}_{\mathrm{O}}$ where thermal diffusion is larger for the 20CO2Hemix and 60CO2Hemix flames due to the helium component. However, as $\mathrm{Le}_{\mathrm{O}}$ did not have a large effect on the flame growth rate, a viable explanation is that radiative energy transfer by $\mathrm{CO}_{2}$ played a role in transfer of energy to the far field.

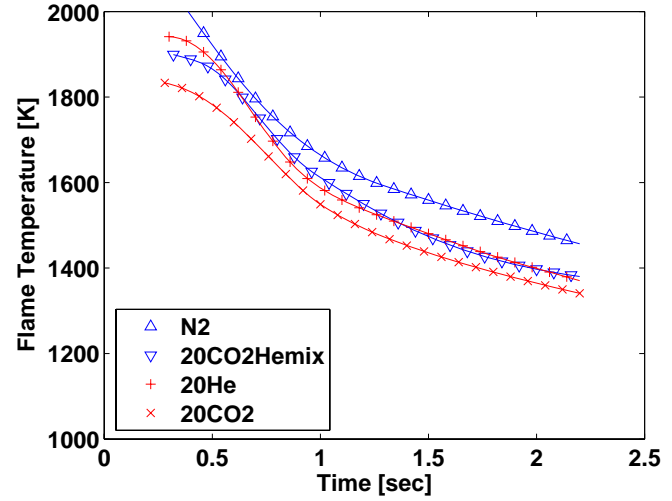

Figure 5. Flame temperature $[K]$ versus time fit estimated from thermocouple peaks at the flame passed through the thermocouple array for $20 \%$ diluent flames.

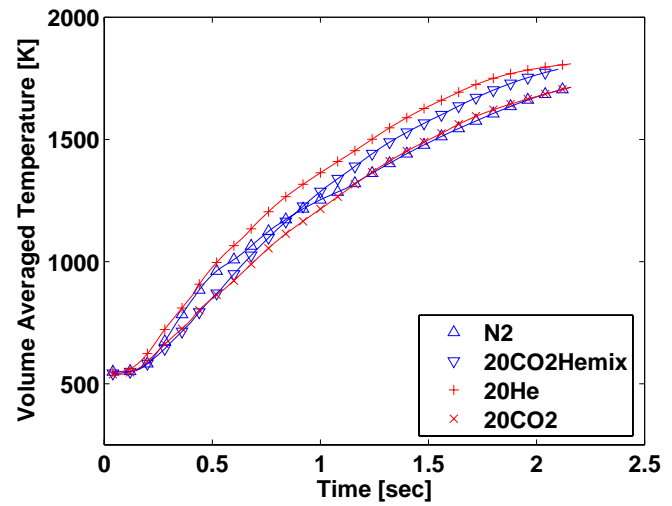

Figure 7. Volume averaged temperature [K] versus time fit calculated from eight discrete measurements for $20 \%$ diluent flames.

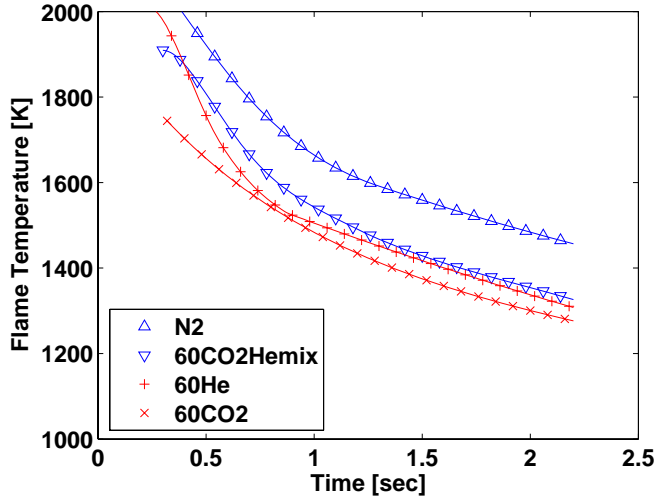

Figure 6. Flame temperature $[K]$ versus time fit estimated from thermocouple peaks at the flame passed through the thermocouple array for $60 \%$ diluent flames.

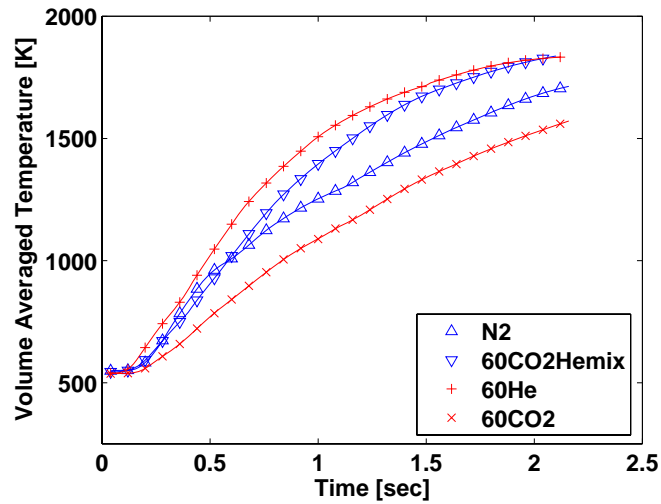

Figure 8. Volume averaged temperature [K] versus time fit calculated from eight discrete measurements for $60 \%$ diluent flames.

Comparing the $\mathrm{N} 2$ and 20He flames in Figs. 4 and 5, the overall flame temperature of the 20He flame decreased by almost $100 \mathrm{~K}$. In Fig. 4, the N2 and $20 \mathrm{He}$ flames had equivalent interior temperatures shown by TC $1-3$ although the $20 \mathrm{He}$ flame is seen by TC 5 - 7 to have increased far field temperature onset and gradients with a difference greater than $150 \mathrm{~K}$ over that of the N2 flame. Consistently, the N2 flame with the $60 \mathrm{He}$ flame in Figs. 4 and 6, the $60 \mathrm{He}$ flame had a lower flame temperature by $150 \mathrm{~K}$. In Fig. 4 , up to a $50 \mathrm{~K}$ increase in the interior flame temperatures of the $60 \mathrm{He}$ flame was observed in $\mathrm{TC} 1$ in comparison to the $\mathrm{N} 2$ flame. Despite the lower flame temperature of the $60 \mathrm{He}$ flame, significantly enhanced far field temperature onset and gradients were observed with a temperature difference by as much as $300 \mathrm{~K}$ over the N2 flame in Fig. 4. Furthermore, the $20 \mathrm{He}$ and $60 \mathrm{He}$ flames had a higher volume averaged temperature (Figs. 7 and 8) in comparison to the N2 flame indicating increased heat release. The observations of increased far field temperatures and increased heat release indicate that increased thermal diffusion is taking place. One would expect the helium flames to have an increased adiabatic flame temperature over that of the nitrogen flame, yet the thermal transport is dominating the decreased thermal capacity 
of the mixture. There may be some significance into the curvature of the $60 \mathrm{He}$ volume averaged temperature shown in Fig. 8. This observation merits further study.

Comparing the $\mathrm{N} 2,20 \mathrm{CO} 2$, and $60 \mathrm{CO} 2$ flames in Figs. $4-6$, the overall flame temperature of the $20 \mathrm{CO} 2$ and $60 \mathrm{CO} 2$ flames are decreased by $100 \mathrm{~K}$ and $200 \mathrm{~K}$, respectively, in comparison to the $\mathrm{N} 2$ flame. This is to be expected due to the increased heat capacity or $\rho C_{P}$ of the $\mathrm{CO}_{2}$ diluent with respect to the $\mathrm{N}_{2}$ diluent. Comparing the interior temperatures of the $20 \mathrm{CO} 2$ flame to the $\mathrm{N} 2$ flame (Fig. 4, TC 1-3) indicated slightly lower interior temperatures by about $25 \mathrm{~K}$ despite the much lower flame temperature (Fig. 5). Consistent results are observed when comparing the $60 \mathrm{CO} 2$ flame to the $\mathrm{N} 2$ flame in Fig. 4. The increased interior temperatures suggest that radiation reabsorption is taking place by the $\mathrm{CO}_{2}$ in the interior region of the flame. The $20 \mathrm{CO} 2$ flame had higher far field temperatures by about $50 \mathrm{~K}$ in comparison to the $\mathrm{N} 2$ flame (Fig. 4, TC $5-7$ ). The $20 \mathrm{CO} 2$ and N2 flames had approximately equivalent volume averaged temperature (Fig. 7). This suggests increased radiative transport to the far field occurred because thermal diffusivity is low and the volume averaged temperatures are approximately equivalent. Equivalent far field temperatures (Fig. 4 TC 5-7) were observed for the $60 \mathrm{CO} 2$ and the N2 flames despite the lower flame temperature. This result consistently supports the hypothesis of radiative transport. The $60 \mathrm{CO} 2$ flame had a decreased volume averaged temperature in comparison to the N2 flame (Fig. 8) which indicates lower heat release. Though the two results seem inconsistent it could indicate that there are competing effects: (i) enhanced radiative transport due to increased $\mathrm{CO}_{2}$ concentration in the flame region, and (ii) lowered burning intensity due to the high heat capacity of the $\mathrm{CO}_{2}$ diluent. The interesting phenomena that occurred in the temperature field results warrant further investigation into the burning intensity of these flames.

\section{Flame Radiation}

Radiation intensity results for radiation bands in the visible and infrared regions are presented in Figs. 9-11. Due to interference of the hotwire igniter on the results during ignition, data during the ignition regime were omitted.

Figure 9 shows the radiation intensity in the visible, 0.4 - $1.2 \mu \mathrm{m}$ wavelength range, primarily indicating high temperature soot radiation. The standard deviation of the visible intensity measurements was found to be on average $15 \%$ of the signal. Ethylene, the fuel used in this study, has great potential to produce a sooty flame as seen by the N2 flame in Fig. 9. Soot formation was decreased with the $20 \mathrm{He}, 20 \mathrm{CO} 2 \mathrm{Hemix}$, and 20CO2 flames but was still present. For the $60 \mathrm{He}, 60 \mathrm{CO} 2 \mathrm{Hemix}$, and $60 \mathrm{CO} 2$ flames, soot was suppressed completely. The N2 flame initially had a large increase in soot formation and luminous intensity after ignition established a blue flame. As the diffusion flame moved outward seeking oxygen, the flame temperature decreased and soot formation was inhibited. Soot was pushed away from the flame region due to thermophoresis. Reduced temperatures of the interior region allowed the soot to cool, thus reducing the visible emission intensity.

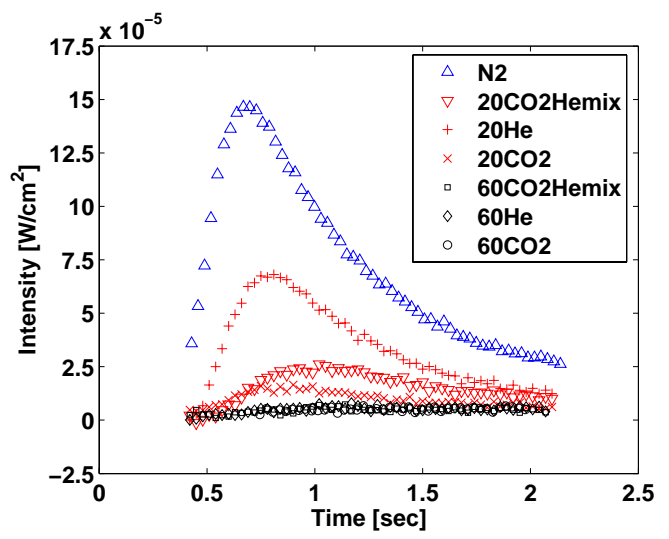

Figure 9. Visible $(0.4-1.2 \mu \mathrm{m})$ radiation intensity measurement $\left[\mathrm{W} / \mathrm{cm}^{2}\right]$. Intensity primarily due to high temperature soot.

Figures 10 and 11 show radiation intensity in the infrared region, $3-5 \mu \mathrm{m}$, wavelength range. This region indicates trends in $\mathrm{CO}_{2}$ emission with small contributions from soot and unburned hydrocarbons. The standard deviation of this intensity measurement was found to be on average $4 \%$ of the signal. The intensity measurement in Figs. 10 and 11 indicate that the intensity was leveling off. Comparing the 20CO2Hemix and 60CO2Hemix flames with the N2 flame in Figs. 10 and 11, the CO2Hemix flames have approximately 15\% lower intensity than the N2 flame. Despite having a higher volume averaged temperature (Figs. 7 and 8) the CO2Hemix flames emitted less radiation in the $\mathrm{CO}_{2}$ sensitive band. It was noted in section 3-B that the $\mathrm{CO} 2 \mathrm{Hemix}$ flames could have increased thermal diffusion due to the helium but also have an effect of increased radiative transfer due to the $\mathrm{CO}_{2}$ in the atmosphere. The lower intensity results suggest that this increase in transferred energy from the flame was subsequently reabsorbed by the $\mathrm{CO}_{2}$ enhanced atmosphere.

The $20 \mathrm{He}$ and $60 \mathrm{He}$ flames come to an equivalent intensity with the N2 flame as seen in Figs. 10 and 11. While the helium flames had a lower flame temperature, they had higher volume averaged temperature indicating increased heat release. In section 3-B it was found that this was a thermal diffusion energy transport and the intensity results are consistent with this finding. There seems to be no significant radiation reabsorption of energy from the $20 \mathrm{He}$ and $60 \mathrm{He}$ flames over that of the $\mathrm{N} 2$ flames. 


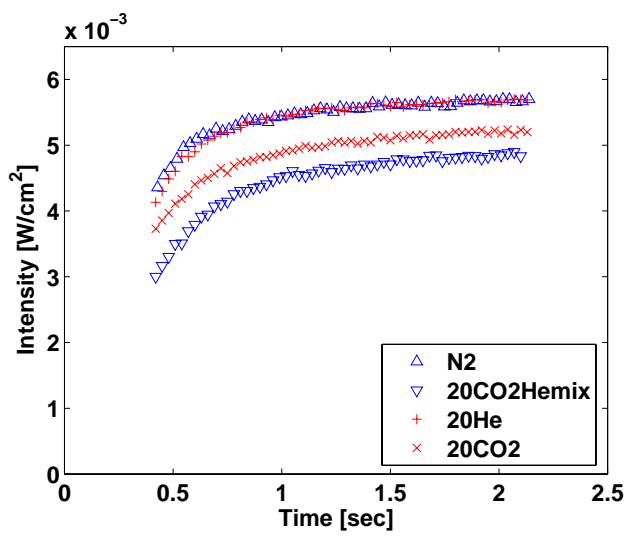

Figure 10. Infrared $(3-5 \mu \mathrm{m})$ radiation intensity measurement $\left[\mathrm{W} / \mathrm{cm}^{2}\right]$ for $20 \%$ diluent flames. Intensity primarily due to $\mathrm{CO}_{2}$ emission with contributions from soot and unburned hydrocarbons.

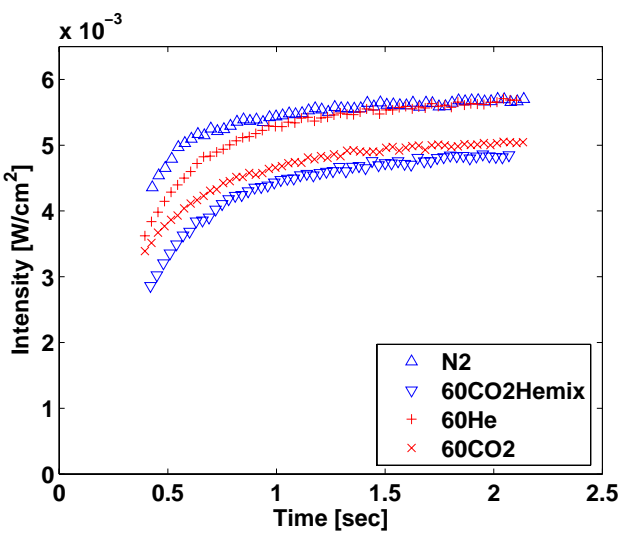

Figure 10. Infrared $(3-5 \mu \mathrm{m})$ radiation intensity measurement $\left[\mathrm{W} / \mathrm{cm}^{2}\right]$ for $60 \%$ diluent flames. Intensity primarily due to $\mathrm{CO}_{2}$ emission with contributions from soot and unburned hydrocarbons.

The 20CO2 and 60CO2 flames both had decreased intensity in comparison to the $\mathrm{N} 2$ flame as seen in Figs. 10 and 11. Because of the much lower flame temperature and the lower volume averaged temperature as discussed in section 3-B, the results do not clearly indicate whether this is an effect of the lower heat release or a factor of radiation reabsorption. Further study is warranted of additional experimental results for these $\mathrm{CO}_{2}$ diluent flames.

\section{Conclusion}

This work presents the results of experiments designed to improve understanding of the effects of radiation absorption on the $\mu \mathrm{g}$ flames. Flame growth rate, temperature field, and radiation measurements are discussed in this work to demonstrate the effects of $\mathrm{CO} 2$ and/or Helium as diluents on the oxidizer side of the reaction zone of transient spherical gaseous diffusion flames in microgravity.

Experimental results show that Lewis number of the oxidizer does not have a dominant effect on flame growth. Influence of a $\mathrm{CO}_{2} / \mathrm{He}$ mixture despite controlling $\rho \mathrm{C}_{\mathrm{P}}$, the energy storage component of the reactant mixture in for comparison with $\mathrm{N}_{2}$ diluent, reduced soot formation and flame temperature due to increased energy transfer. The $\mathrm{CO}_{2} / \mathrm{He}$ mixture increased the volume averaged temperature and lowered the flame emission indicating both an increase in heat transfer and reabsorption of the energy. Helium diluent lowered the flame temperature, increased the volume averaged temperature, and maintained flame emission. $\mathrm{CO}_{2}$ diluent lowered the flame temperature, decreased the volume averaged temperature, and also lowered flame emission.

\section{Acknowledgments}

This project was supported by NASA under the Microgravity Combustion Program.

\section{References}

${ }^{1}$ Atreya, A., Agrawal, S., Sacksteder, K.R., and Baum, H.R., 32nd Aerospace Sciences Meeting \& Exhibit, 94, AIAA, 1994.

${ }^{2}$ Atreya, A., and Agrawal, S., Combust.Flame, 115 (1998) 372-382.

${ }^{3}$ Tse, S. D., Zhu, D., Sung, C-J., Ju, Y., and Law, C. K., Combust. Flame, 125 (2001) 1265-1278.

${ }^{4}$ Christiansen, E.W., Tse, S.D., and Law, C.K., Combust. Flame 134 (2003) 327-337.

${ }^{5}$ Sunderland, P.B., Axelbaum, R.L., Urban, D.L., Chao, B.H. and Liu, S., Combust. Flame 132 (2003) 25-33.

${ }^{6}$ Bendir, H., T'ien, J.S., and Lee, H.S., Combust. Theory \& Modelling 1 (1997) 395-404.

${ }^{7}$ Ju, Y., Masuya, G., and Ronney, P.D., Proc. Combust. Inst. 27 (1998) 2619-2626.

${ }^{8}$ Kazakov, A., Conley, J., and Dryer, F.L., Combust. Flame 134 (2003) 301-314.

${ }^{9}$ Ruan, J., Kobayashi, H., Niioka, T., and Ju, Y., Combust. Flame 124 (2001) 225-230.

${ }^{10}$ Du, D.X., Axelbaum, R.L. and Law, C.K., Proc. Combust. Inst. 23 (1990) 1501-1507.

${ }^{11}$ Zhang, C., Atreya, A. and Lee, K., Proc. Combust. Inst, 24 (1992) 1049-1057.

${ }^{12}$ Lee, C.E., Lee, S.R., Han, J.W., and Park J., Int. J. Energy Res. 25 (2001) 343-354.

${ }^{13}$ Liu, F., Guo, H., Smallwood, G.J., and Gülder, O.L., Combust. Flame, 125 (2001) 778-787. 
${ }^{14}$ Chernovsky, M.K., and Atreya, A., "Radiation, Temperature and Soot Measurements in Transient Spherical Microgravity Diffusion Flames," Experimental Thermal Fluid Science (to be published).

${ }^{15}$ Kee, R.J., Rupley, F.M., and Miller, J.A., "Chemkin-II: A Fortran Chemical Kinetics Package for the Analysis of Gas Phase Chemical Kinetics,” Report No. SAND89-8009B, Sandia National Laboratories, 1987.

${ }^{16}$ Kee, R.J., Dixon-Lewis, G., Warnatz, J., Coltrin, M.E., and Miller, J.A., "A Fortran Computer Code Package for the Evaluation of Gas-Phase Multicomponent Transport Properties," Report No. SAND86-8246, Sandia National Laboratories, 1986. 